\title{
How Managers Can Create Happy Working Environment
}

\author{
Denisa ABRUDAN ${ }^{1}$ \\ Iulia CONEA-SIMIUC ${ }^{2}$
}

\begin{abstract}
Do you know that happy employees are one of the most significant factor when you think about productivity and satisfied customers?

It is important to analyze if the benefit packages offered by today's companies are tailored to the needs of the employees. Historically, there has been a strong correlation between wealth and happiness, so are the benefit packages good enough in order to be a factor in attract and retain the outstanding employees that show commitment towards work?

Can these benefits impulse the employees to achieve superior output at work? Will the employees be happier and relying on this state, to overcome their limits in everyday job tasks?

A proposal in order to achieve this state of happiness among the employees would be to provide a tailored system of $C \& B$ that meet the employees' expectations, system, which also includes the well-being concept.

According with a study realised by Social Market Foundation in 2015, happy employees are up to $20 \%$ more productive than unhappy employees. When it comes to sales people, happiness has an even greater impact, raising sales by $37 \%$. But the benefits don't end there, also happy employees will have better decision-making abilities and greater innovation abilities, also will be a reduction in lost productivity and better customer service.

The present paper work describes, within theoretical aspects and a practical case, the role of occupational welfare in having happy, committed employees and successful organizations.
\end{abstract}

Keywords: employee's commitment,well-beeing, organization, productivity, manager

JEL classification: M10, M12, M16

DOI: $10.24818 /$ RMCI.2019.3.286

\section{Introduction}

Recently, more and more employers address the welfare of employees from a psycho-social and physical point of view, while realizing that this can turn into a genuine competitive advantage over competition.

\footnotetext{
${ }^{1}$ Denisa Abrudan Ph.D West University of Timisoara, Faculty of Economics and Business Administration

${ }^{2}$ Iulia Conea-Simiuc, Frigoglass Romania SRL
} 
The concept of employee welfare means more than taking the necessary measures to prevent their physical illness, is a complex system that addresses both their mental state and their physical condition (Chartered Institute Of Personnel And Development,Growing the health and well - being agenda: from first steps to full potential. Policy report, 2019).

Personal welfare makes sense in a social context. In recent years, the lives of individuals have been affected by many social, professional, existential changes, but despite these changes, people still have the same basic physical and mental needs: social support, physical security, health and the feeling of being capable of successfully managing aspects of everyday life (Happiness and productivity: Understanding the happy-productive worker, Social Market Foundation, Warwick University, 2015).

Welfare is a concept that reflects on the organization as a whole, and in order to maintain and improve it, it is necessary to implement integrated policies that involve all members of the organization, from top management to executives/blue collars (Morgan L., 2019).

\section{Physical well-being - the result of a healthy and balanced lifestyle}

Physical well-being refers to the status of the physical condition of the individual. Every person must be able to carry out specific activities related to everyday life, without being limited to any kind of somatic disorder. Clearly, physical well-being does not coincide exclusively with the absence of a disease or a condition, but is the result of a healthy and balanced lifestyle that the individual has acquired.In the organizational environment, physical well-being must be among every employer goals, through all the measures that he can implement so as to help keep his employees in good physical condition.

In this sense, an essential role is played by ergonomics science and its principles, which seeks to establish the optimal ratio between the requirements of the job description and the employee's ability to achieve them. The main purpose is to adapt working conditions so that they are in line with the employee's abilities. Of course, there is also the option of engaging employees in trying to improve their physical skills for professional purposes. The last one, however, is a wrong approach that is nothing more than a pretext for maintaining inadequate working conditions or a derogatory working environment (World Health Organization, Preventing Muskuloskeletal Disorders at Work, 2003).

In order to preserve the optimal physical form of employees, it is advisable to find a balance between periods of physical activity and rest periods. The workload attributed to each employee must be based on age, gender, professional training, general health, so as to avoid both underload or employee overloading.

Working conditions need to be continuously analyzed and improved, and employees should be trained on a regular basis about desirable behaviors to avoid injuries and illnesses. The ergonomic design of the workplace must be such that the employee takes a correct body position while working, using different support 
elements to correct deviations of posture (to have adjustable height and adjustable elbows working chairs / tables). Equally important are the elements of the physical environment, such as lighting, ventilation and temperature.

Even though some health risk factors, such as hereditary ones, can not be changed, education and discipline can help combat other factors that affect health: smoking, sedentary, alcohol, weight gain. Depression, anxiety, migraines, respiratory diseases, arthritis, diabetes, sore throat and back pain are some of the diseases that contribute to decreasing productivity. Employees suffering from more than one concomitant illness are the most vulnerable in matter of productivity ( Schaufeli W. B., Salanova M., 2014).

Absenteeism caused by health problems is a clear factor in decreasing productivity. The same negative impact, however, is also the presence at the workplace in illness or stress condition, and as a result the employees will not be productive (Chişu V. A., Bucureşti, 2002).

Beyond measures related to workplace design, safety and health, business organizations must be the promoters of a healthy lifestyle among employees.

All these measures can be successfully implemented only by the power of the example. Employees will not attend a wellness program if their application is strictly for financial reasons (to reduce the company's health insurance costs) or to avoid financial loss caused by absenteeism.

\section{Mental well-being - the key to the employees involved and performed}

Mental well-being, as defined by the Mind, refers to the mental state of the individual (Mind, 2018). Mental welfare is a dynamic concept. For example, an individual can be considered as having an acceptable mental state despite the existence of mental illness. A good mental state implies the following aspects:

- to have self-esteem and self-confidence;

- feel and express a diverse range of emotions;

- build and maintain good interpersonal relationships with others;

- be connected to the world around you;

- to live and work productively;

- to cope with the stress of everyday life, including occupational stress;

- have the ability to adapt in unsafe times defined by continuous change.

Employers must develop programs to maintain health and wellbeing at work in accordance with the needs expressed by employees. The content of these programs and how to access them must be clearly communicated. Individuals also need to be self-reliant to take advantage of the company's benefits and to be concerned about maintaining their physical and mental well-being in and outside the workplace.

Prior to implementation, these programs need to be debated in order to inform and involve employees in the change process. Any changes to be introduced to the company must be made clear and transparent to all the personnel. In fact, the 
easiest way to combat potential resilience to change is to directly engage employees in transformation processes.

If all of the above guidelines will be implemented, work will become an attractive space where productivity and corporate responsibility predominate.

Creating a well intend culture that supports wellbeing at the workplace, not by reducing absenteeism and its costs, but by implementing health-centered policies and healthy choices that will ensure staff retention, will raise the level of involvement, productivity and performance (Mathis R.L., Nica C.P., Rusu C.,1997).

Employees who are well-off are both physically and mentally capable of actively engaging in the workplace, adding value to their work (Chartered Institute Of Personnel And Development, 2016).

\section{Financial welfare - from standard to personalized}

For a very long time, the rewarding of employees involved the fulfillment of legal obligations towards the employee (salary payment, granting of leave and other types of holidays, payment of social and health insurance, etc.).

Recently, however, companies have concluded that, in order to attract, motivate and develop the employees, they must design a "tailor-made" reward systems that rely on and meet the individual needs of each employee. However, according to a Deloitte study (Deloitte, 2017), most companies are having difficulties to do so.

The reward system is in a transition phase, from standard to personalized. In order to develop a system that meets the needs of the employee to meet their expectations, companies need to establish strong personal relationships with each employee. Companies that manage to develop and implement such systems are those who will acquire and maintain the competitive advantage. However, only a small number of companies (9\%) managed to make this move.

It has been shown that employees respond positively to those initiatives that require wage increases, performance bonuses and other incentives more often than once a year. It is demonstrated that the employees who regularly receive small financial rewards in cash or appreciation are up to 8 times more involved than those employees who receive bonuses only once a year.

Companies are wrong when they choose not to align salary increases to the frequency with which they perform employee performance ratings. According to Deloitte research, $20 \%$ of companies evaluate employee performance a few times a year, but only $9 \%$ of companies also adjust wages at the same frequency. Most remuneration schemes are rigid and based strictly on criteria such as experience or seniority in the workplace.

Another aspect related to financial well-being is that too few employees perceive the remuneration system as being fair. Most employees believe that the way salaries and other benefits are established is completely arbitrary, which negatively affects staff retention and turnover rates - staff turnover. Many studies 
show that employees who do not understand how the salary is set are more likely to leave the organization.

At present, employee expectations regarding performance rewards and fairness have increased, claiming that these issues are transparent and flexible, especially in the context of employee free access to wage information through platforms like would be Glassdoor or Linkedin.

Employees today want financial reward systems to match and reflect their way of living, working and communicating rather than being anchored in the past when the same set of measures was applied to all, regardless of expectations and the needs of each individual.

From this perspective, employees must be treated as if they were customers of the company: they must be valued and the quality of their experience with the organization needs to be continually improved. The organization must take into account what employees want, without supposing they know what they want, the things they need or what is good or right for them.

\section{Labor force - characteristics and trends}

The population in Europe is experiencing an aging process: the population aged 65 or over increase by 2.4 percent between 2007 and 2017 as a result of low birth rates and high life expectancy, which means that people retire later, the number of years you work increases from 32.9 years in 2000 to 35.6 years in 2016 .

Europe's labor force faces an accelerated aging rate, which means that exposure to occupational risks increases proportionally to the length of the years spent in the workforce. Despite this perspective, the older generation of employees should not be seen as a vulnerability, but on the contrary, companies need to appreciate and capitalize on the level of expertise and years of experience they have accumulated.

On the other hand, there are significant changes in the structure of the labor force, as the millennia - members of the Y generation (1981-1996) - account for more than half of the total labor force in many countries. Until 2025, the millenniums will account for $75 \%$ of the total available labor, according to a Deloitte study.

This category of employees, in the process of professional development, gives twice the importance of self-care, as opposed to the baby boom generation (1946-1964). Millennials value life style, living, motivated by continuous, professional and personal development. All of these personal values are also imported into the professional environment in which they work, which gives rise to new standards that organizations must achieve.

Generation Y is seconded by young generation Z (born since 1997) who are new to the labor market, making the transition from student or student to employee status. Pragmatic, they do not think they will have a better or happier life than their parents had. However, they are motivated by professional and personal 
development, while at the same time desiring to expand their passion by translating it into the work what they like.

In a few words, the principles, values and expectations of the two generations are as follows:

- Millennials seek professional stability, job security, exciting and stimulating work, a convenient work schedule, work-life balance, lifelong learning;

- Those belonging to the $\mathrm{Z}$ generation want exciting and stimulating work, be part of a company that they can boast, work with passion, have all the information they need to be able to perform their job duties and lifelong learning.

- For business organizations to be able to retain workers from these generations, they must:

- Provides career development / career advancement opportunities;

- Mentoring from senior managers in the company or management;

- Provides the opportunity to contribute to projects, to be creative;

- Create an organizational culture that demonstrates that it attaches importance to the work-life balance concept;

- Build a brand that values labor ethics and social responsibility;

- Promote a creative environment that supports the achievement of personal development goals;

- Ensures professional stability.

Financial security is one of the most important factors considered by both the $\mathrm{Y}$ generation and the $\mathrm{Z}$ generation as a result of high unemployment rates, competitive labor market and professional career instability. Other factors that include members of the generations are organizational culture and inclusiveness.

Considering the sets of values and principles of the new generations that shape the workforce as well as their fears, employers could support young Y generation employees by providing support for completing their studies, providing ongoing professional training, creating the necessary framework for career development.

For young generation $\mathrm{Z}$, they can be supported by paying extra attention to their mental health.

\section{Illustrative case}

An applied research realised within a multinational company in Romania, a global supplier of energy and data management products, solutions and services in the field of automotive and other industrial fields in Romania, which aims at analyzing the extent to which the welfare of employees is ensured (physical, psychic, and financial) shows interesting aspects.

Employees know what their duties are according to job description, contributing to the diversity of training methods provided by the company, the most common of which are: on-the-job training (through initial training, and then,

\begin{tabular}{lll}
\hline Review of International Comparative Management & Volume 20, Issue 3, July 2019 & 291
\end{tabular} 
through internal operational procedures), e-learning or shadowing - a method by which a new employee closely follows the work of a senior colleague in the company, in order to take over part of his activities.

Employees also feel that they have the necessary framework to be able to develop professionally. This is possible due to one of the company's core principles, named"internal mobility" - a process by which employees are internally promoted to other positions within the organization, thus giving them the chance to advance their career.

Given that there are employees who do not know what professional results they should achive, management should address this issue distinctly when giving job assignments or when evaluating individual performance.

Regarding the way of work, most of those surveyed say the activity they are doing is stimulating, they can practice their professional skills, especially the creative side and the ability to identify solutions to the problems that arise, proving their utility. The intense and significant work contributes greatly to ensuring the employee's well-being at the workplace. Such an employee will show a high level of satisfaction, involvement and productivity at work.

However, over a quarter of the surveyed employees - especially those with little seniority - said that they have to perform monotonous and repetitive tasks. This can lead to dissatisfaction at work, low returns, high absenteeism rates and, finally, high turnover rates - all of which create economic pressures on the organization.

In order to minimise the adverse effects that may arise from this, management should consider rotation of jobs or diversification of service tasks by offering the opportunity to be part of projects that require increased creativity to the extent that nature activity allows it.

Employees benefit from normal work schedules and are generally not required to provide overtime. In cases where, however, they happen to be forced to work over the usual work schedule, they are limited to spending one to two hours at work. They also do not have to work in shifts, nights or weekends.

The work schedule is fixed in the sense that it does not undergo spontaneous changes except in some cases and then employees are notified the same day or even a few days before.

Since an atypical work program (extended program, night shift, shift work, work on a Saturday or Sunday) is one of the main determinants of the imbalance between work and personal life, we can see that, at least from this point of view view, the employees are not in the situation of the impossibility of reconciling the two aspects.

Also, the predictability of the work program (a fixed work program that is not subject to change - especially the last time) is a guarantee that work will not interfere with the employee's personal life.

Flexible working arrangements are increasingly found in job offers as a mean of helping employees find a balance between work and personal life. Whether we are talking about tele-work, flexible schedule or short week, all of 
these arrangements make a significant contribution to improving the experience that employees have in working with the company.

Within the company, most of the employees (68\%) benefit from flexibility. From this point of view, the company is above the European average, where less than one third of employees have the choice of predefined work programs.

Even if most employees benefit from flexible working arrangements, more than half of them say they do not feel encouraged by their bosses or colleagues to use them. This percentage falls into the European trend.

Although there are some interferences of professional obligations in personal life, some respondents claiming to be concerned about job duties even in leisure time, employees have the ability to harmonize their professional and family spheres.

Like employees in other European countries, employees of the company also state that work-life balance can be achieved by reducing the number of hours spent at work. From here it can be concluded that what has worked in the past could prove to be effective in the future. Thus, individuals further believe that fewer hours devoted to work could help them to focus more and, at the same time, on qualitative issues on family / personal life.

Regarding the organizational climate, employees say they can communicate effectively with their managers. Communication should be improved by strengthening team spirit - although employees say that when they are overwhelmed by high volumes of work, which must be done in unreasonable time, they benefit from support from both colleagues and managers. In this sense, the company could encourage the organization of teambuilding as a formal way to connect the team.

Also, the company's management should listen and value employee improvement suggestions, as they are best aware of the work gaps.

Considering that most of the respondents are members of the $\mathrm{Y}$ generation, it is important for them to have a pleasant work environment, opportunities for professional growth andjob security. Corroborating the values and principles that guide the company with the answers to the other questions, it is concluded that in the organizational environment, these needs of the employees in general and those of the Y generation in particular are ensured.

A popular choice is the organizational culture that valorizes the concept of work - life balance, given that the millenarians are very much committed to the adopted lifestyle, attaches great importance to their health and social life, working to live and not vice versa .

In terms of physical well-being, employees are generally sedentary and have an unbalanced diet. However, they want a good lifestyle change, and think they could do so if they enjoyed free access to fitness classes and fruit and vegetables from the company. According to a 2016 study, the human body needs daily 60 to 75 minutes of physical activity to alleviate the negative effects of sedentary work. 
The company offers the possibility of performing medical analyzes at low prices. While this is an obvious benefit, the company should have a prophylactic approach by promoting a healthy lifestyle through a balanced nutrition.

All of these benefits should be implemented through a reward system, considering that strict implementation would generate opposite effects to those expected, employees loosing confidence in the company's intentions when forced to do things against their will.

The company should pay more attention to training employees on the suitable behaviour in order to avoid the risk of occupational disease - which could be caused by prolonged exposure to the screens or the development of musculoskeletal disorders due to inappropriate dosing of working periods and rest during a business day. In addition, the company must provide employees with furniture and other ergonomic equipment to prevent or mitigate occupational hazards associated with office work. In this regard, one can see the example of the Dutch company SAP, which invested in ergonomic alternatives for office furniture, such as: adjustable height tables that allow the individual to work both seated and sitting or bicycles, version of the elliptical bicycle, adapted to the corporate environment.

There are a number of workplace and activity-specific factors that indicate an increased risk of burnout syndrome among employees. Thus, in almost equal proportions, they said they were facing a great deal of work, very tight deadlines, without receiving feedback from the management and without being able to participate in the decision-making process. This risk is somewhat under control as employees receive regular professional training and career development opportunities, and can also be based on the social support of colleagues in busy times.

In terms of financial well-being, the company has not yet made the transition to the personalized payroll system. Employee performance performances at present are much more often than the frequency with which wages are increased, for example. Employees are awarded annual performance bonuses on the basis of quarterly assessments made by meeting the individual and organizational criteria that are brought to their attention through a one-to-one, employee and team leader discussion.

The payroll system is characterized as rigid, with a large number of employees not knowing how to set wages and other benefits. According to studies, this may represent a turnover risk. Thus, the company has to consider the transparency of wage issues. For example, in order to promote transparency and trust, Cisco's American company regularly compels its compensation and benefits to market competitors on a regular basis, giving employees an insight into the pay of each occupational family in the company reported to competitors.

Another example of good practice is that of a textiles manufacturing company that created three variants of pay: increasing the basic salary for employees demonstrating alignment with the company's core values; providing bonuses to meet specific goals; incentives and actions for those who demonstrate 
leadership skills and adhere to 360 degree feedback - a process through which not only hierarchical superiors provide feedback on the work of the employee concerned, but also peers, customers and even the employee himself.

The flexibility of this remuneration system enables employees to decide whether they want to focus on teamwork, on achieving specific goals, or on guiding leadership roles (Lovell Corporation, 2017).

\section{Conclusions}

An increasingly questionable fact in the minds of organizational managers now arises in the digital age that could mark the end of traditional work - the famous program 9 to 5: How should occupational well-being be approached? Are the benefit packages outlined by today's companies sufficient to attract and retain the talented workforce that shows commitment to work? Or will the future come under unconventional approaches already tested by some companies like Netflix or Virgin? Who can definitely know the answer.What we can say, however, is that there is a need for a rethinking of the business.

Companies will have to give their employees unconditional freedom thanks to technological innovations. So employees do not have to be in the office under the strict supervision of managers, and what matters is the final result they deliver, not the number of hours spent at the company's headquarters. Employee freedom is also extended to leave, with the employee having the opportunity to take free time when he feels the need and the need, without pre-approved requests or other formalities.

Will we see such changes in the workplace?

Many companies already do this. More and more employees calibrate the work-life balance as they please, without affecting in any way the company's business, becoming fully responsible for their own well-being.

\section{References}

1. Chişu V. A. (coordonator) - Manualul specialistului în resurse umane, Casa de Editură IRECSON, Bucureşti, 2002

2. Chartered Institute Of Personnel And Development,Growing the health and well - being agenda: from first steps to full potential. Policy report (online) Londra, 2019 https://www.cipd.co.uk/Images/health-well-being-agenda_2016first-steps-full-potential_tcm18-10453.pdf

3. Chartered Institute Of Personnel And Development, 2016 https://www.cipd. co.uk/Images/health-well-being-agenda_2016-first-steps-full-potential_tcm1810453.pdf

4. Deloitte. At a tipping point? Workplace mental health and wellbeing, 2017 https://www2.deloitte.com/content/dam/Deloitte/uk/Documents/publicsector/deloitte-uk-workplace-mental-health-n-wellbeing.pdf 
5. Happiness and productivity: Understanding the happy-productive worker, Social Market Foundation, Warwick University, U.K, 2015 http://www.smf.co.uk/wp-content/uploads/2015/10/Social-MarketFoundation-Publication-Briefing-CAGE-4-Are-happy-workers-moreproductive-281015.pdf \#page $=9$

6. Lovell Corporation, How Millennials and Generation $\mathrm{Z}$ are Redefining Work. Research, 2017

https://www.lovellcorporation.com/wpcontent/uploads/The2017ChangeGenerationReport-Lovell-Corp.pdf

7. Mathis R.L., Nica C.P., Rusu C. - Managementul resurselor umane, Editura Economică, Bucureşti 1997

8. Mind, How to improve your mental wellbeing, 2018 https://www.mind. org.uk/information-support/tips-for-everyday-living/wellbeing/\#.XPgjj4gza1s

9. Morgan Lovell, What is employee wellbeing, London, 2019 https://www.morganlovell.co.uk/knowledge/checklists/what-is-employeewellbeing/

10. Schaufeli W. B., Salanova M., An Introduction to Contemporary Work Psychology, First Edition. Editura John Wiley \& Sons, Ltd, 2014 https://www.wilmarschaufeli.nl/publications/Schaufeli/416.pdf

11. World Health Organization,Preventing Muskuloskeletal Disorders at Work. Geneva, 2003 https://www.who.int/occupational_health/publications/en/ oehmsd3.pdf 